\title{
Rectal-Colitis Caustic Stenosing by Enema to Traditional Products: About a Case
}

\section{Sawadogo Yamba Elie ${ }^{1 *}$, Ouangre Edgar ${ }^{1}, Z_{i d a}$ Maurice${ }^{1}$, Sama Gui ${ }^{1}$, Bande Youssouf ${ }^{2}$, Kafando Roch1, Bonkoungou Gilbert ${ }^{2}$, Sam Aristide1, Traore Si Simon' ${ }^{1}$}

${ }^{1} \mathrm{CHU}$ Yalgado Ouédraogo, Ouagadougou, Burkina Faso

${ }^{2} \mathrm{CHU}$ Blaise Compaoré, Ouagadougou, Burkina Faso

Email:*elicomfr@yahoo.fr

How to cite this paper: Elie, S.Y., Edgar, O., Maurice, Z., Gui, S., Youssouf, B., Roch, K., Gilbert, B., Aristide, S. and Simon, T.S. (2018) Rectal-Colitis Caustic Stenosing by Enema to Traditional Products: About a Case. Open Journal of Gastroenterology, 8, 154-158.

https://doi.org/10.4236/ojgas.2018.84017

Received: January 5, 2018

Accepted: April 27, 2018

Published: April 30, 2018

Copyright $\odot 2018$ by authors and Scientific Research Publishing Inc. This work is licensed under the Creative Commons Attribution International License (CC BY 4.0).

http://creativecommons.org/licenses/by/4.0/

\begin{abstract}
The practice of traditional medicine and the use of medicinal plants are increasingly developed in Africa. Its poorly controlled administration often leads to severe complications that can sometimes be life-threatening. Intrarectal injection of caustic material with such purpose as suicide, murder, accident, or as a tribal therapeutic is responsible, within several hours, for burns of the colonic coating, the severity of which ranges from a simple light congestion of the rectal mucosa to a complete necrosis of the colon of variable length from the rectum to the cecum. We report the case of a stenosing rectocolitis complicating enemas with traditional products. Colonoscopy and contrast enema found their interest in determining the limits of surgical resection.
\end{abstract}

\section{Keywords}

Recto-Colitis, Caustic, Traditional, Burkina Faso

\section{Introduction}

Caustic burns of the lower digestive tract are relatively frequent in black Africa and are characterized by high mortality. The practice of enemas is common practice. They are used for therapeutic purposes (chronic abdominal pain, constipation, impotence in men, sterility in women) abortifacient, punitive or criminal and even suicidal [1]. In Burkina Faso, traditional medicines are used by all social classes, but serious accidents, especially digestive, are rare [2]. The caustic recto colitis that they generate is often at the origin of a high mortality in view of the lack of consensus on the precise determination of the operative time [1]. We report a case of stenosing recto-colitis to describe our therapeutic modality. 


\section{Observation}

G M, a 24-year-old patient was referred from the gastroenterology department to the general and digestive department of CHU YO for rectal stenosis. The patient without history of psychiatric disorder reported an enema with traditional products 3 months before using commercial instruments. The nature of the traditional product could not be specified but would treat constipation. Two days after the enema, there appeared abdominal pains and then abundant rectorrhages. These symptoms motivated a specialized consultation in gastroenterology and surgery. The examination found a male patient living in rural areas with a good general condition, a normal consciousness, a painless flexible abdomen without organomegaly. There was a loss of weight of $6 \mathrm{~kg}$ since the onset of symptoms. In rectal examination there was rectal stenosis $3 \mathrm{~cm}$ from the anal margin. The stenosis was impassable at colonoscopy. The contrast enema showed scar narrowing of the anal canal, sigmoid and left colon (Figure 1). The operative indication of a colo-anal lowering has been posed.

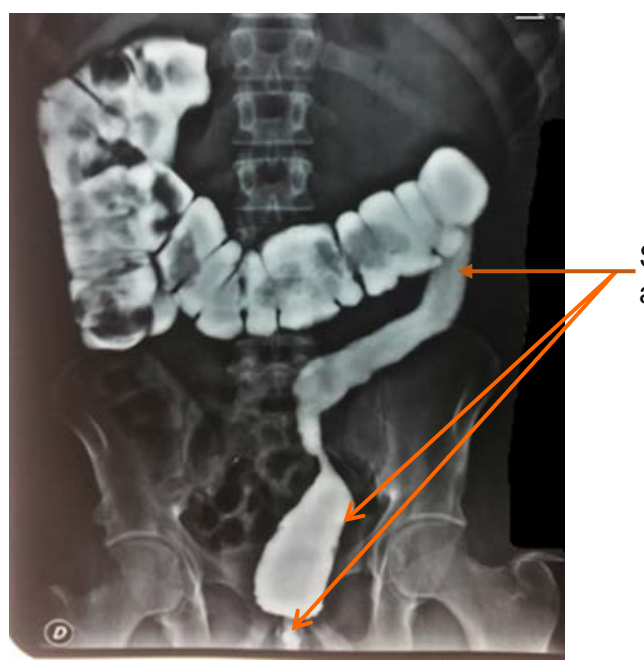

Stenosis of the left colon rectum and anal. Front view

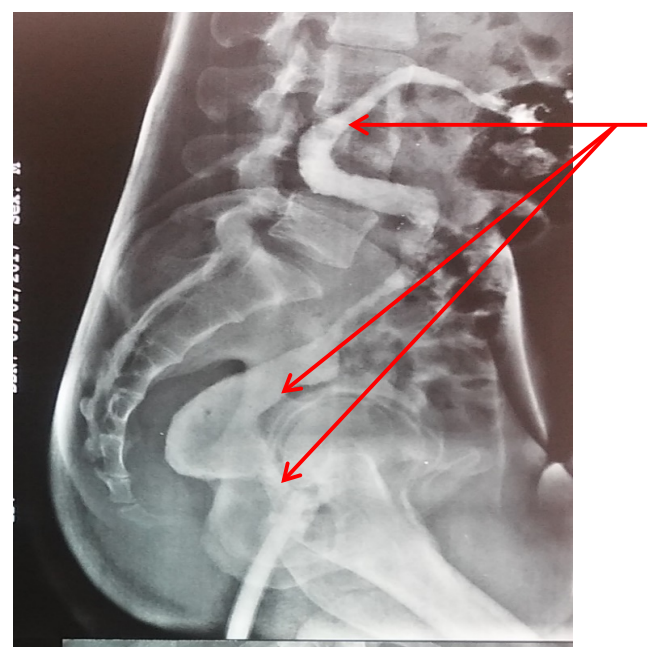

Stenosis of the left colon rectum and anal. Profile view

Figure 1. Enema with contrast products. Face and profile images. 
The operating technique of "modified" SWENSON has been realized. It was in a first abdominal time of the detachment of the entire colon and then in a second perineal period of the section of the terminal digestive tract carrying the stenosis. This maneuver allowed the externalization of all the left colon and rectum, previously released, at the level of the anus (Figure 2). An immediate manual colo-anal anastomosis was performed with resorbable thread. The hospital stay was 4 days. The postoperative course was marked by anal incontinence occurring mainly during sleep. This complication has benefited from sphincter reeducation sessions. The 3-month control noted a satisfactory functional result with a normal anal continence.

\section{Comment}

Complications associated with traditional treatments are common in BURKINA FASO, but severe forms, responsible for surgical abdomen are rare. In 2013, five cases of surgical complications were noted in the general and digestive surgery department of CHUYO [2].

Despair, difficult access to conventional medicine, beliefs, taboos, the low cost of traditional products would explain the easy use of traditional therapy. All African social classes are concerned.

The growing number of traditional healers in our cities (remunerative function) and the rush of city dwellers towards them (because of the fall in purchasing power, despair) will be determining factors of this iatrogenic pathology south of Sahara. The legal recognition of traditional healers, the free sale of home products, the market, on the streets would explain the exaggeration of this practice in our environment and also elsewhere in Africa [1] [2] [3].

Medicinal plants are often poorly controlled by some users whose administration is sometimes life-threatening. From erosive lesions to intestinal perforation, complications due to enema to traditional products are diverse and varied. Caustic burns of the rectum and colon have been published. Serious cicatricial and sequelae complications such as stenosis would imply a surgical procedure sacrificing the entire pathological segment at the cost of a sometimes satisfactory functional result.

Clinical manifestations are mainly represented by abdominal pain, rectal bleeding and occlusive syndrome. Sometimes these signs give way to a torpid picture of abdominal discomfort, bloating and constipation [1] [3]. The clinical characteristics and the antecedents of enema with the traditional products guide the diagnosis and make it possible to specify the paraclinical explorations (Table 1). The indications for colonoscopy are consistent with those reported by most authors, with a predominance of explorations of rectal bleeding [4] [5]. Indications for caustic enema are related in this case to mistakes made in the context of traditional local practices of evacuating enemas using traditional pharmacopoeial decoctions for the purpose of treating or preventing constipation. The enema with the contrast product was of a great contribution. X-ray images revealed 


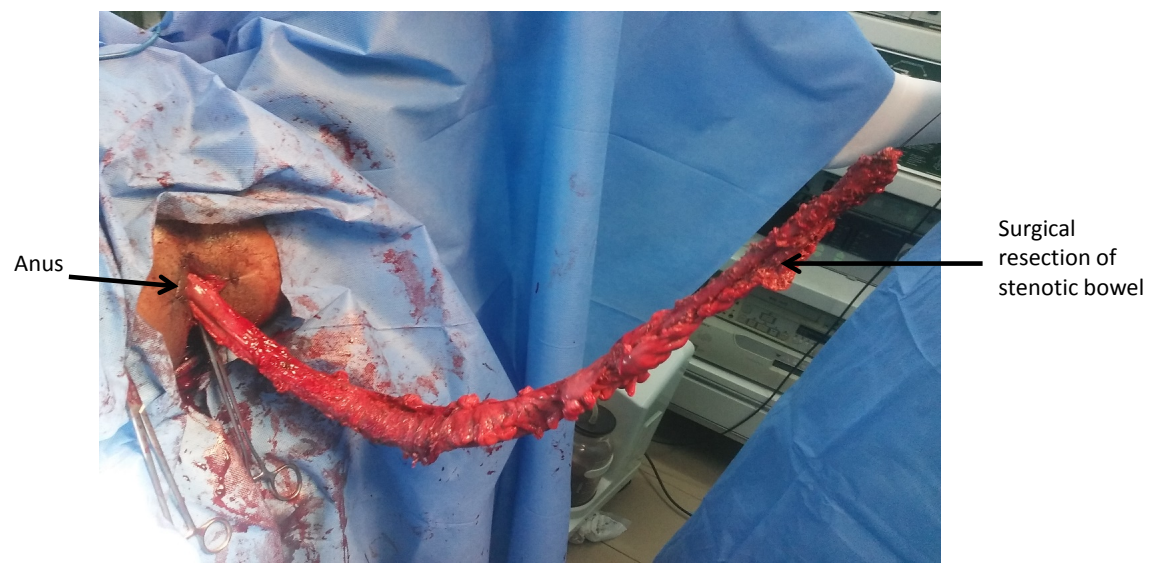

Figure 2. Anal, rectal and left colic mobilization through the anus in the prone position.

Table 1. Sociodemographic and clinical characteristics.

\begin{tabular}{|c|c|c|c|c|c|c|}
\hline Old/Sex & residence & $\begin{array}{l}\text { Time of } \\
\text { consultation }\end{array}$ & Etiology & Symptoms Colonoscopy & $\begin{array}{l}\text { Contrast } \\
\text { enema }\end{array}$ & $\begin{array}{l}\text { Hospital } \\
\text { stay }\end{array}$ \\
\hline 24/Male & $\begin{array}{l}\text { Rural } \\
\text { areas }\end{array}$ & 3 months & $\begin{array}{l}\text { Enema to } \\
\text { traditional } \\
\text { products }\end{array}$ & $\begin{array}{l}\text { Abdominal } \\
\text { pain } \\
\text { Rectorrhagy impassable } \\
\text { Anal ste- } \\
\text { nosing }\end{array}$ & $\begin{array}{l}\text { scar } \\
\text { narrowing of } \\
\text { the anal } \\
\text { canal, } \\
\text { sigmoid and } \\
\text { left colon }\end{array}$ & 4 days \\
\hline
\end{tabular}

the degree of stenosis and the extent of the lesions. Scar narrowing was pronounced at the anus, sigmoid, and left colic angle. The lesions can appear above healthy areas for several reasons: the speed of administration, the quantity and nature of the product administered, the anatomical storage areas and the evacuation rate. Thus certain anatomical portions are spared either by the absence or the weak contact with the caustic product or by the speed of expulsion responsible for minor lesions.

In the context of severe digestive causative lesions, survival is closely related to the time between ingestion and surgical treatment. With respect to the reasonable limits of resection, it is difficult to specify a numerical limit. We refrain from any excision in case of necrosis of the small intestine requiring excision incompatible with a nutritional autonomy and in case of extensive colonic necrosis. In these cases, the chances of survival are very low and especially, in such a case, the long-term future would be compromised by nutritional problems and reconstruction [6]. In our case, the caustic lesions extending from the left colic angle to the anal canal allowed complete excision compatible with satisfactory functional results.

\section{Conclusion}

Severe complications of enemas with traditional products require special vigilance and monitoring. Medico-surgical management sometimes resulted in amputation of the lower digestive tract. The reduction of this morbidity and mor- 
tality necessarily involves sensitizing the population and training traditional healers. It would be necessary for traditional products used in therapies to be the subject of pharmacological studies in order to guarantee the health of users.

\section{References}

[1] Casanelli, J.-M., Rebecca, B. and Keita, M. (2016) Recto colite caustique nécrosante grave : à propos d'un cas. Revue Internationale des Sciences Médicales, 18, 301-303

[2] Zida, M., Zan, A. and Ouangré, E. (2013) Les abdomens chirurgicaux dus au traitement traditionnel. À propos de cinq cas au Centre hospitalier Yalgado Ouédraogo de Ouagadougou. Bull. Soc. Pathol. Exot.

[3] Diarra, B., Roudie, J., Somian, F.E. and Coulibaly, A. (2004) Caustic Burns of Rectum and Colon in Emergencies. The American Journal of Surgery, 187, 785-789. https://doi.org/10.1016/j.amjsurg.2003.10.019

[4] Thibaud, D., Kouate, M. and Wiser, I. (2001) Rectorragies: complication d'un lavement à l'eau oxygénée. Archives de pédiatrie, 8, 1267-1248. https://doi.org/10.1016/S0929-693X(01)00642-X

[5] Okon, J.B., Assi, C., Diakite, M. and Siaka, K. (2012) Coloscopie pédiatrique : expérience du centre hospitalier universitaire de Cocody (Côte d'Ivoire). Médecine et Santé Tropicales, Vol. 22, N8 2-avril-mai-juin.

[6] Munoz-Bongrand, N., Cattan, P. and de Chaisemartin, C. (2003) Brûlures digestives extensives par caustiques: Quelles limites à l'exérèse? À propos de 12 patients. Annales de chirurgie, 128, 373-378. https://doi.org/10.1016/S0003-3944(03)00113-5 